\title{
Anterior Occiput Presentation
}

National Cancer Institute

\section{Source}

National Cancer Institute. Anterior Occiput Presentation. NCI Thesaurus. Code $C 92732$.

A fetal position during delivery in which the head of the fetus faces the mother's back. 